\title{
On the Possibility of a Paratelic Initiation of
}

\section{Organizational Wrongdoing}

\begin{abstract}
In terms of reversal theory, both dominant and alternative explanations of the initiation of organizational wrongdoing assume that its perpetrators act in a telic state of mind. This leaves us with explanations of organizational wrongdoing that are insufficiently appreciative of the agent's experience. The human mind can be creative and imaginative, too, and people can fully immerse in their activity. We suggest that the paratelic state of mind is relevant for the phenomenological understanding of the initiation of original, creative, daring courses of action, and that the paratelic state of mind may originate courses of action that social control agents, at a later moment in time, may label as organizational wrongdoing. Our proposal is especially relevant when organizational agents are on a course of exploration, facing uncertainty, complexity, and unavailability of information.
\end{abstract}

\section{Keywords}

Arousal; Exploration; Reversal Theory 
Don't play the game by the rules. Change it. - KPMG advertisement, Copenhagen Airport, November 2015

With his small joke, the stupidest of all ideas became reasonable, even almost sensible, maybe even genius. The alternative-sanity-became insane. - Jonathan Safran Foer (2016), Here I Am, Hamish Hamilton, p. 387

\section{Introduction}

Organizational wrongdoing is often understood as behavior that is perpetrated by (groups of) organizational members who act on behalf of the organization, and that is deviant in the sense that it violates criminal, civil, or administrative law, transgresses explicit industry or professional codes, or contravenes less codified organizational rules, social norms, and ethical principles (Vaughan, 1991; Palmer et al., 2016). The question of how agents [1] initiate organizational wrongdoing has been addressed extensively in the behavioral ethics literature (Tenbrunsel and Smith-Crowe, 2008; Greve et al., 2010; Palmer, 2012). The question of the initiation of organizational wrongdoing is distinct from questions of its spread and perpetuation through processes such as normalization (Ashforth and Anand, 2003), gradual escalation (Fleming and Zyglidopoulos, 2008), and socialization (MacLean, 2008), all of which presume that some wrongdoing has already occurred.

In naturalistic research settings, the question of the initiation of wrongdoing can only be answered post hoc when the researcher has learned about an agent's course of action. The result is an inadequate understanding (Locke and Golden-Biddle, 1997) of the agent's experience in the situation in which s/he finds her/himself (Warren and Smith-Crowe, 2008). The agent may have two kinds of experience, both of which have not been taken into account in extant explanations of the initiation of organizational wrongdoing. First, the agent may experience considerable, if not fundamental, uncertainty and ambiguity around the morality of a course of action, or in deciding which course of action would be morally optimal (cf. aporia, Derrida, 1992). This implies that even if -or precisely because- s/he has a well developed moral awareness and imagination and normal cognitive abilities, s/he may still not 
be able to derive the morally correct course of action. Second, the agent may experience arousal and excitement stemming from being fully immersed in her/his activity, especially when s/he is exploring a novel course of action. This experience of arousal may prevent the agent from engaging in moral deliberation.

Palmer's (2012) classification of explanations of the initiation of organizational wrongdoing as "dominant" and "alternative" offers an illustration of our critique. His classification critically hinges on the assumed motivation of the agent. Dominant explanations assume that organizational wrongdoing is produced by "mindful and rational actors who deliberate in social isolation, make discrete decisions, and develop positive inclinations to engage in wrongdoing” (Palmer, 2012, p. 3, p. 91). In such explanations, the agent is aware of the morality of her/his (intended) course of action and then "mindfully" decides to pursue it. By contrast, alternative explanations assume that organizational wrongdoing is produced by "mindless [...] actors, who formulate their behavior in an immediate social context, in a temporally protracted escalating fashion, and who never develop positive inclinations to engage in wrongdoing” (Palmer, 2012, p. 3, p. 89). In alternative explanations, the agent "mindlessly" conforms her/his behavior to pressures stemming from administrative systems, structural power differences or situational social influences, perhaps subordinating her/his own moral intuition and judgment to these external forces.

Either way, there is little place in the explanation for the agent's experience of doubt, ambiguity or uncertainty. The possibilities that wrongdoing originates from accident or from social control agents changing the standard by which they judge, do not change our analysis. Rather, it is in line with our suggestion that the agent may not know, due to uncertainty or ambiguity, if a course of action will be labeled as morally right or wrong at a later point in time. 
Neither does the agent's experience of arousal, when s/he is fully engaged in activity, play a prominent role in dominant and alternative explanations. The mindful agent is predominantly seen as calculative, lacking emotion when he decides to do wrong. The mindless agent may intuitively understand from experiencing moral emotion "that a potential action is to be pursued or avoided” (Moore and Gino, 2015, p. 250). Yet, we argue that arousal can suppress moral emotion that otherwise might "point [the agent] in specific behavioral directions and amplify the strength of [her/his] moral judgments” (Moore and Gino, 2015, p. 251).

Although both dominant and alternative explanations of wrongdoing have empirical traction, we find their motivational assumptions "inadequate" in the sense of "not sufficiently incorporating different perspectives and views of the phenomena under investigation” (Locke and Golden-Biddle, 1997, p. 1047). This is notably the case when the agent faces complexity, uncertainty, and lack of information related to unbeknownst future events and developments, such as in the activity of exploration. Exploration (March, 1991), which is at the core of strategic management, new venture creation, and innovation, demands the agent to be creative, to think out of the box. This demand makes the activity and its outcomes potentially valuable and productive, but also risky, in both material and moral terms. [2] A fuller understanding of the agent's experience helps to understand how exploration results in the initiation of novel courses of action; social control agents, once they have learned about them, may label some of them as excellent, commendable, and praiseworthy, but others as inappropriate, irresponsible, and objectionable - that is, as instances of organizational wrongdoing. Thus, our research question is: How may the initiation of organizational wrongdoing be understood if we start from the agent's experience?

In addressing this question, we draw on the psychological theory of motivation known as reversal theory, in particular on its treatment of arousal (Apter, 1989; 1991; 2007). The reversal theory treatment of arousal is relevant, because it directly theorizes how people may 
become engaged and excited in their doings. It explains how people may become creative, imaginative, and playful, and how they develop a sense of invulnerability and lose attentiveness to future consequences and moral considerations. It is especially relevant when people face complexity, uncertainty, and ambiguity in their exploration of novel courses of action.

Our overarching contribution is to argue for the relevance of reversal theory to understand the initiation of organizational wrongdoing. We propose an account of the initiation of organizational wrongdoing that recognizes how exploration inherently involves creativity, imagination, and playfulness. This may lure exploration into the realm of make-believe, in which its participants lose sight of and sensitivity to the moral dimensions of their proposals and decisions. Our argument complements dominant and alternative explanations of the initiation of organizational wrongdoing and further speaks to emerging research on ethics and creativity (Moran et al., 2014; Muhr, 2010).

We develop our argument in the following way. First, we modify the consensus approach in conceptualizing organizational wrongdoing by highlighting the experience of the agent. Second, we shortly introduce reversal theory in order to be able to discuss, subsequently, dominant and alternative explanations in light of reversal theory. Next, we propose a stylized account of the initiation of organizational wrongdoing that is based on the treatment of arousal in reversal theory. We conclude with a summary of our argument and discuss implications.

\section{Organizational Wrongdoing}

To define 'organizational wrongdoing' is a challenging task, which is perhaps a reason why many studies of moral behavior do not offer a definition of wrongdoing (Smith-Crowe and Zhang, 2016). Studies that do offer a definition rely on either of two approaches. In one 
approach, labeled "essentialist” (Warren and Smith-Crowe, 2008; or “exegetical,” Palmer, 2012), the researcher defines upfront what s/he considers wrong (or right) in some course of action. S/he can do so by relying on a criterion or principle that finds its justification in moral philosophy, theology or social critique. The essentialist approach can be criticized on the ground that there is no general agreement about the question which criterion or principle reflects moral truth or has universal validity (cf. Smith, 1993; Palmer, 2012). Absent a moral truth, the researcher's choice remains subjective.

The researcher may circumvent the uncertain foundation of the essentialist approach by focusing on behaviors that many people readily do or likely would agree are wrong, such as lying and cheating (Smith-Crowe and Zhang, 2016, p. 20) and various forms of fraud and other transgressions of the law. "In this respect, wrongdoing is generally operationalized as behaviors that authors assume readers will accept as fitting these broad definitions [i.e., violation of ethical principles, social norms, administrative rules, or civil and criminal law] and that will be uncontroversial” (Palmer et al., 2016, p. 9). In this move, the essentialist approach is turned into a "consensus" (Warren and Smith-Crow, 2008; or "sociological," Palmer, 2012) approach. Although relativist in comparison to the essentialist approach, it does have the advantage of obtaining empirical grounding, as it bases itself on how, in a social setting, social control agents do judge that some behavior is morally wrong.

The consensus approach has its limitations, too. Most importantly, social control agents make their judgment after the fact, once they have learned of an agent's course of action. Thus, the consensus approach allows the researcher to address the question of how social control agents come to label a course of action as wrong (e.g., Graffin et al., 2013), but it turns away from the agent in explaining the initiation of wrongdoing. By approaching wrongdoing from the perspective of the social control agent, "previous research has overlooked the pervasive ambiguity in ethical situations in organizations” (Warren and Smith-Crowe, 2008, p. 81) and 
therefore "we do not know much about the experience of the transgressors themselves" (Warren and Smith-Crowe, 2008, p. 82). Warren and Smith-Crowe (2008) study how well meaning employees, who are suddenly confronted with the fact that they have unknowingly transgressed in the eyes of others, revise their moral judgment due to the experience of embarrassment or (threat of) sanction. This analysis gets Warren and Smith-Crowe closer to the agent's experience, but their analysis is still after the fact.

From the perspective of the agent, it may not always be clear whether a course of action will turn out to be in violation of the criteria, principles, or standards held by a social control agent, even if the agent has a well-developed sense of morality or ability in moral reasoning. That is, we do not assume that the agent has an under-developed moral imagination (Werhane, 1999), that s/he is a priori subject to bounded ethicality (Chugh et al., 2005), or that s/he has a deficient mental capacity, low self-control, or an antisocial personality disorder (Palmer, 2012, p. 54). Instead, there can be considerable or even fundamentally irresolvable uncertainty about the question whether a course of action violates or subverts existing rules. In this context, Palmer (2012, p. 8) speaks of the "thin line separating wrongdoing from right-doing.” Yet, the metaphor of a thin line may be misleading in suggesting that there is a clear distinction between right and wrong, whereas the agent may well experience, even in deliberation, that some course of action is associated with an unsorted, entangled mesh of both right and wrong. Managerial action, such as in devising compensation systems (Larking and Pierce, 2016) or in promoting organizational identification (Vadera and Pratt, 2016), can be associated with wrongdoing by some employees and with right-doing by other employees, for example. Further, the judgment by social control agents is not reflective of a moral truth but socially constructed, for example in a macro-level discourse in public media (Graffin et al., 2013; Clemente et al., 2016), adding to the uncertainty and ambiguity in the agent's deliberation. Agents cannot oversee the full 
material and moral consequences of their courses of action or the social control agents' future judgment of their courses of action.

This implies that there is no clear, objective distinction between organizational mistake, organizational misconduct, and organizational disaster, because they are "socially defined in relation to the norms of some particular group," such that their definition may "vary by level of analysis" and that they are defined "only in retrospect when outcomes are known" (Vaughan, 1999, p. 283).

Therefore, for this paper, we rely on the consensus approach to define organizational wrongdoing. But we modify it by changing its perspective to the agent's, which allows us to highlight her/his experience. The agent can be supposed to have some understanding of how social control agents might, could, would, or perhaps should come to their judgments (given their professed standards and assuming that they are not corrupt, Sherman, 1980). Although the agent may thus have some orientation to understand whether or why social control agents might consider a course of action to be wrong, our approach recognizes the uncertainty and ambiguity that the agent may experience regarding the future judgment by social control agents. Such uncertainty and ambiguity is even more pronounced when the agent is involved in organizational action that implies or demands exploration (March, 1991). From this vantage point, we can start to theorize the possibility of an understanding of the initiation of organizational wrongdoing that is complementary to dominant and alternative explanations. It should be noted that our argument may not be relevant to the entire range of possible types of organizational wrongdoing. If corruption is a specific category of wrongdoing at the interface with public authorities (Sherman 1980; Torsello and Venard, 2016) and not synonymous with organizational wrongdoing (e.g., Ashforth and Anand, 2003; Zyglidopoulos and Fleming, 2008), then corruption is outside the scope of our argument; Its initiation is typically with civil servants in public authorities who rarely if ever engage in the 
kind of exploration that is central to our theorizing. Neither do we have in mind organizational misbehavior when that concept refers to "anything you do at work you are not supposed to do," including "the widest range of behavior-from failure to work very hard or conscientiously, through not working at all, deliberate output restriction, practical joking, pilferage, sabotage and sexual misconduct” (Ackroyd and Thompson, 1999, p. 1-2). Such behaviors are interpersonal actions that violate norms of conventional social behavior (Lefkowitz, 2006, p. 249), essentially the opposites to organizational citizenship behavior (Organ, 1988) and other forms of prosocial organizational behavior (Brief and Motowidlo, 1986).

Before we can discuss current explanations of the initiation of wrongdoing in light of reversal theory, we first offer a brief introduction to reversal theory.

\section{Reversal Theory}

Reversal theory (Apter, 1989; 1991; 2007) is a psychological theory of motivation that has analyzed, among other topics, the various ways in which people experience arousal. This strand of reversal theory has been developed as a critique of optimal arousal theories. Optimal arousal theories hold that individuals are motivated to reach and perform best at their optimal level of arousal. Reversal theory, by contrast, suggests that individuals do not aim for one optimal level of arousal, but that depending on their state of mind, they can experience both low and high levels of arousal as pleasant. Reversal theory distinguishes two states of mind in relation to arousal: telic and paratelic. Both are constantly available, but people can only be in one state at a time. Whichever their state of mind, it may reverse to the other for various reasons, which we discuss after having defined the telic and paratelic states of mind. "The telic state is defined as a state of mind in which one conceives oneself to be pursuing an important goal, the behavior being subsidiary and chosen to achieve the goal” (Apter, 1989, 
p. 22). Apter (1991, p. 16) adds: "In the telic state the end determines the means, the means being used simply in the attempt to attain the end. Thus, some need is recognised, or goal chosen, and then a suitable activity is selected which is intended to produce satisfaction of this need or attainment of the goal.” People in a telic state of mind experience a low level of arousal as pleasant and a high level of arousal as unpleasant. Apter uses the nouns "relaxation" and "anxiety” as general descriptors of these two situations, respectively, and argues that people in a telic state of mind seek relaxation and avoid anxiety. The attainment of an important goal requires focus and concentration of effort. Their ability of attaining it is enhanced when their effort is undisturbed (relaxation), whereas they become anxious and will seek other means to attain their goal when it is disturbed by unexpected events. Apter (1989, p.22) uses the example of somebody walking to arrive in time for an important interview, but then, when "it begins to appear that one will not achieve this goal, one will choose some other means (for example, take a taxi).”

By contrast, "The paratelic state of mind is one in which the orientation is toward the behavior itself, together with its concomitant sensations, in this case any goal being conceived as subsidiary and essentially an excuse for the behavior. In other words, there is a sense in which [...] the ongoing activity is at the focus in the paratelic state” (Apter, 1989, p. 22). People in the paratelic state of mind act in the moment; they are excited, involved, creative, playful (Apter, 1991). In the paratelic state of mind, a high level of arousal is experienced as pleasant, whereas a low level of arousal is experienced as unpleasant. Apter uses the nouns "excitement" and "boredom" as general descriptors of these two situations, respectively. People in the paratelic state of mind seek excitement and avoid boredom. There is no goal to be attained, just the activity to be enjoyed. In the example of somebody walking, one may walk for the sake of walking and "if in this case it turns out that one's destination is beyond one's reach in the time available, one will simply choose another destination, while 
continuing with one's walk” (Apter, 1989, p. 22). The activity may become a more exiting experience if one unexpectedly encounters a friend long not seen, or a rare animal species if one is an amateur of nature. In fact, the walker may choose to walk along a path that increases the chances of such encounters and thereby the experience of excitement in the activity. More generally, people in the paratelic state seek to do activities that offer high levels of excitement, which may involve the chance of unexpected encounters, challenges, and problems, taking risks, and facing dangers.

The paratelic state of mind is not just associated with individuals, but can develop among a group of people (Apter, 2017). Huizinga's (1955) discussion of how participants (and sometimes their spectators, too) may become fully encapsulated in an intense and concentrated game is suggestive of the possibility of a shared paratelic state of mind. Winnicott (2005) argues that playfulness is relational and self-reinforcing; in interaction playfulness tends to provoke further playfulness, similar to the self-reinforcing increase in creativity during a productive brainstorm session.

The paratelic state of mind is more likely than the telic state of mind to induce the person (or group of persons) to explore new possibilities within and for its activity, but also to take its consequences less seriously (Apter, 1989, 1991, 2007). In the paratelic state of mind, activity becomes a phenomenological experience in which self-consciousness diminishes and improvisational potential is enhanced (Feezell, 2013). The paratelic state of mind is associated with the experience of flow (Csikszentmihályi, 1990; Wright, 2016), in which a sense of the self is lost to the joy of perpetuating the activity at hand (Winnicott, 2005). Although this phenomenological experience has been highlighted as a defining characteristic of play (e.g. Huizinga, 1955), Apter (1991) insists that the paratelic state of mind is not restricted to leisure and play, but instead, that it is regularly experienced in all kinds of human activity, including paid work in a job (cf., Feezell, 2013). 
When people are in the paratelic state of mind, a protective frame builds up that reinforces it (Apter, 1991). A protective frame entails the reinforcement of a perspective on risks, dangers, challenges, and problems as excitements to be embraced and enjoyed, rather than as anxieties to be avoided. Moreover, it creates a feeling of invulnerability. There are three types of protective frames: safety-zone, detachment, and confidence (Apter, 2007, pp. 50-51).

In the safety-zone frame, people are so thoroughly engrossed in their activity that their sense of surroundings -including the awareness of risk- fades away. This frame is most closely associated with flow (Wright, 2016). In the detachment frame, people perceive themselves as outside observers to a situation, detached from it, and unaffected by it. In the confidence frame, people's excitement and positive arousal in facing challenges is enhanced by trust in and reliance on their own abilities, equipment, and the people with whom they engage in their activity. It helps them to figure out novel ways of dealing with the challenges they encounter and gives them a sense of mastery over the situation.

The three types of protective frames are distinct, but complementary in being able to reinforce each other, even if, perhaps, the confidence frame is most relevant to activities oriented at exploration, because of its ability to enhance problem solving through devising unorthodox, original solutions. They help sustain the paratelic state of mind and thereby support people to engage and persist in undertaking daring and risky activities.

Although the buildup of a protective frame reinforces the paratelic state of mind and increases its longevity, it can be broken. Apter (2007) discusses frustration, satiation, and contingency as reasons why a protective frame may break, and why consequentially the person reverses from a paratelic to a telic state of mind. Frustration refers to the repeated experience of failure to master a challenge, satiation to the passing of time, as there is a limit to how long one is able to enjoy any activity, and contingency to the unexpected disturbance by some event that is external to the activity in which the person is immersed. The break of a 
protective frame can be temporary and the paratelic state of mind may immediately return when a person takes up again the interrupted activity.

With high positive arousal and a protective frame in place, the paratelic state of mind results in a shared sense of enjoyment and allows for more creative and unorthodox deployments of available skills to meet the challenge at hand. This enables participants to think of and explore propositions that would not always make sense or be readily accessible for people in the telic state of mind. The paratelic constitutes a break away from telic constraints: the analytical means-ends analysis and care about the wider consequences of action.

\section{Explanations of the Initiation of Organizational Wrongdoing in Light of Reversal}

\section{Theory}

Based on this brief sketch of reversal theory we can now appraise the extant literature that seeks to explain the initiation of organizational wrongdoing in light of reversal theory. We rely on Palmer’s (2012) distinction between dominant and alternative explanations. [3] Dominant explanations of the initiation of wrongdoing include rational choice and strain theories. Rational choice explanations maintain that agents are opportunistic, for example in exploiting information asymmetries. Strain theories predict that people will seek illegitimate means of achieving their aspirations when legitimate means are blocked and when the (shortterm) benefits outweigh (long-term) costs and risks. Such explanations critically assume that the agents are rational beings: mindful and deliberate, the knowing and willing trespassers of laws, codes, rules, and norms under conditions of opportunity or strain (Maclean, 2008; Palmer, 2012).

Although often used, dominant explanations of organizational wrongdoing remain limited (Palmer, 2012). First, they insufficiently acknowledge that people are rationally and ethically bounded (Chugh et al., 2005) and subject to non-cognitive influences such as intuitions, 
feelings and emotions. Second, they can be mistaken in viewing ethical decision making as an isolated one-off event, instead of viewing it as embedded in and entangled with other decision making processes and social situations.

A series of alternative explanations address some of these concerns by proposing how organizational members, while focusing on task accomplishment, may unwillingly become wrongdoers. For example, they may make a mistake, an accident may happen, or a social control agent may change its standard of judgment. They may also become implicated in wrongdoing when they -mindlessly but obeying- conform to pressures stemming from administrative systems, structural power differences, or situational social influences (Palmer, 2012). Their wrongdoing is unintended; they have no control over the circumstances and conditions of their work.

In terms of reversal theory, both dominant and alternative explanations assume that agents act in a telic state of mind. When decision-making is done in a telic state of mind, decision makers are future-oriented, purposeful, anxiety avoiding, detached, and professional. The agents that figurate in dominant and alternative explanations both pursue important goals. The protagonists in dominant explanations operate in a rational, deliberative, and calculative manner. They are mindful in knowingly and willingly employing means that are illegitimate, deceitful, and potentially harmful to others. Their action is self-serving, or "self-serving by proxy" when it "serves the policies, directives and/or aims of the organization, not one's own personal interests” (Lefkowitz, 2006, p. 247). The protagonists in alternative explanations are equally telic, but their important goal is to accomplish the tasks given them. They are mindless in conforming to their situation.

Although both sets of explanations do have empirical validity, they attribute too much mindfulness to a few abnormal people and too little mindfulness to all the normal others. In addition to the telic mindfulness of willful perpetrators and their self-serving calculus of 
instrumental rationality (as per dominant explanations) and the telic mindlessness of submissive organizational members that conform to their immediate local context (as per alternative explanations), there is also the possibility of paratelic creativity and imagination, especially when people get fully immersed in their activities.

We suggest that the paratelic state of mind is relevant for understanding the initiation of courses of action associated with exploration (March, 1991), which are at risk, at a later moment in time, of being labeled by social control agents as instances of organizational wrongdoing. In the next section, we elaborate our proposal.

\section{Exploration and the Paratelic State of Mind}

"Exploration includes things captured by terms such as search, variation, risk taking, experimentation, play, flexibility, discovery, innovation” (March, 1991, p. 71). More generally, it "involves searching for and trying new ways of doing things" (Miller and Ireland, 2005, p. 22). Exploration “engages individuals and organizations in search, experimentation, and variation” (Lavie et al., 2010, p. 110). There is widespread belief that exploration is crucial to organizational success and longevity, and therefore central to strategic management, innovation, and the creation of new business ventures (Lavie et al., 2010). Exploration helps organizations to overcome challenges, venture novel grounds, and do things radically different (Hamel, 1996; Ramírez and Mannervik, 2016), as it takes organizations beyond "their current knowledge base and skills” (Lavie et al., 2010, p. 114).

Although March (1991) -and many scholars after him- argues for a balance between exploration and exploitation, he is critical of exploitation. March argues, on the one hand, that many organizations tend to prefer exploitation over exploration (because exploitation has more predictable outcomes) and, on the other hand, that exploitation "degrades organizational learning in a mutual learning situation [which in turn] leads to convergence between 
organizational and individual beliefs” (March, 1991, p. 85). Exploration is therefore to be promoted, but at the same time, it is -almost by definition- a form of deviant behavior, as it seeks to disrupt the status quo and its outcomes are uncertain.

The pursuit of novelty has a complex relationship with ethics (Moran, 2014). There is a dark side to exploration as it may turn into "foolishness", which is to be "inhibited by reason" (March, 1991, p. 73). March arguably refers to foolishness in economic terms, but he might also have referred to it in moral terms. Yet, instead of a priori considering novelty and creativity in exploration as inherently immoral, we delve into the agent's experience of the practice of exploration, in order to show how exploration has qualities and affordances that may work to decenter moral considerations.

\section{Exploration Entails a Paratelic State of Mind}

Exploration is not just associated with a paratelic state of mind, it invokes and relies on it. This is due to its dealing with epistemic uncertainty, to its tools and technologies, and to it being an activity that is separated in space and time from exploitation.

Epistemic uncertainty. Exploration seeks to condition future organizational successes. As a kind of prognostic activity, exploration is confronted with an epistemic uncertainty: it seeks to know what it cannot know. As the future state of affairs has not yet happened, there is the insurmountable problem of the combination of uncertainty, complexity, and unavailability of information, and all the more so when the future is more distant and in an environment that is more uncertain, complex, and variable. Exploration cannot rely on extrapolation from the present. The future is, at best, in a stage of becoming (Tsoukas and Chia, 2002) and what exploration can deliver is therefore but a phenomenological anticipation of what might be (Vesa and Franck, 2013). Epistemic uncertainty in exploration offers space for intuition as a "holistic hunch" (Miller and Ireland, 2005). In bridging the present and the future, exploration requires imagination and creativity (Smircich and Stubbart, 1985; Mintzberg, 
1994). Imagination helps one to deal with the epistemic uncertainty, because "imagination represents things that are absent [i.e. the future and knowledge thereof]; imagination unifies the empirical and the ideal [i.e. strategy goals, business plans, ambitions]; and imagination fills out and extends incomplete experience [i.e. the future as not yet experienced]" (Weick, 2005, p. 427).

Therefore, exploration works with knowledge that is conjecture, speculative supposition. It may have started as the telic pursuit of an important goal, but the lack of epistemic certainty makes it likely that the organizational members engaged in exploration reverse to the paratelic state of mind. Vice versa, their paratelic state of mind facilitates the workings of intuition, creativity, and imagination. Therefore, exploration entails a paratelic state of mind.

Dedicated tools and techniques. Whilst the future cannot be known, it can be anticipated, enacted, or played out through the use of dedicated tools and techniques to help bridging the present and the future. Among them are strategic scenario planning, simulations, visions, road maps, and strategic back-casting. They are designed to facilitate and stimulate imagination to make sense of an unknown future.

Occasionally, organizations seek to stimulate the creativity and imagination of employees engaged in exploration. For example, the chairperson of strategy workshops -the CEO, a top manager, a facilitator from a prestigious consultancy firm- makes use of techniques and interventions developed in small-group psychology to stimulate a paratelic state of mind among the participants, for example in brainstorming. This further encourages the practitioners of exploration, implicitly or explicitly, to reach out for grander, more grandiose (Alvesson and Gabriel, 2016) future worlds that might be.

These tools and techniques are squarely in the domain of the paratelic state of mind, as the very reason why they can be effective -stimulus of imagination- makes no sense and cannot 
be made productive in a telic state of mind. In fact, they have a recursive relationship with the paratelic state of mind: they stimulate it and they rely on it.

Organizational and temporal separation. Exploration is separated, organizationally and temporally, from the ordinary, day-to-day organizational practices that exploit competences, competitive positions, and economies of scale and scope (Hodkingson et al., 2006; Jarzabkowski and Seidl, 2008; Lavie et al., 2010). In many organizations, exploration has become the turf and responsibility of professionals with special competencies and status (March, 2006). Such exploration professionals are often employed in dedicated organizational units. Exploration can also done during dedicated events, such as strategy workshops and away-days. Participation in them is embellished with substantial prestige, due to being located off the organization's premises and to having restricted participation. In new business ventures, exploration is largely prior to the as-yet unrealized, inexistent operational stage of the venture. Also in established organizations, exploration is prior to exploitation even if occasionally unexpected disruptions of exploitation may precipitate explorative activities.

Meetings and workshops for exploration are rituals in and out of themselves (Johnson et al., 2010); their participants are often excited, being out of their daily routines, feeling important as partakers in creating vistas for future success. As pointed out by theorists of play (Huizinga, 1955), this separation from the mundane is a core aspect of rendering an activity playful. In and out of itself, it stimulates a paratelic state of mind.

These three characteristics of exploration -epistemic uncertainty, dedicated tools and techniques, and organizational and temporal separation- are consequential for the experience of its practice. They work to render exploration an activity done for its own sake, because it has little if any empirical grounding but instead needs to rely on imagination in its articulation of aspiration. Further, the use of dedicated tools and techniques gives exploration 
a structure that orients the imagination fully to the articulation of aspiration and associated courses of action. When skillfully used, they help to produce a rounded off, seamless construction of aspiration, but also to build up a protective frame of confidence because they deliver. Simultaneously, the organizational and temporal separation of exploration stimulates the buildup of a protective frame of detachment.

\section{Creation and Retention of Daring Proposals for Courses of Action}

Being paratelic allows exploration to create a world that might be, through which the formulation of radically new courses of action, scenarios of new futures, and speculative ideas becomes possible. There is a focus on aspects of future organizational activity that are hitherto unaccomplished. Therefore, exploration produces proposals for daring courses of action (Miller and Ireland, 2005). But their appraisal, when done in a paratelic state of mind, is different from when it would be done in a telic state of mind. Two qualities of the paratelic state of mind -the selective appreciation of risk and a shortened temporal horizon- may result in retaining proposals for courses of action that in a telic state of mind might be rejected. Exploration not only triggers paratelic playfulness, it also sets the scene for a weakening of telic rationality; objections and reservations that could have been made in a telic state of mind are sidelined or derided as spoilers of developing the big picture.

Selective appreciation of risk. In the paratelic state of mind, the agents' focus in the activity is directed towards the pleasant sense of thrill that arises from their perception of mastering the future. Agents derive their satisfaction from their -potentially false- feeling of controlling risk. It is important to note that in the paratelic state of mind the seeking after danger or riskbased excitement is done for its own sake; it is not based on a rational, telic analysis of the feasibility of accomplishing what has been set out.

The other side of the coin is that this limits the number of risks that are considered in the first place. If some proposed courses of action are risky, in material or moral terms, participants in 
the paratelic state are unlikely to notice them, or if they do, to focus their attention on those risks that they believe they can master and to underestimate the importance of other risks.

The selective appreciation of risk is already implied in March's (1991) discussion of exploration. He notes that the returns of exploration are "systematically less certain, more remote in time, and organizationally more distant from the locus of action and adaption [exploitation]” (March, 1991, p. 73), they are “uncertain, distant, and often negative” (March, 1991, p. 85). However, people tend to underestimate and undervalue risks that are at a longer time distance. Importantly, temporal distance has been argued to increase moral distance, too (Bazerman and Tenbrunsel, 2011, pp. 56-60).

Shortened temporal horizon. Another consequence of paratelic exploration is paradoxical. Whereas exploration attempts to envision unanticipated futures, it actually results in a shortened mental temporal horizon. This is because the paratelic condition is strongly inductive of flow (Csikszentmihályi, 1990), in which the focus of practitioners is on the hereand-now of their activity. Therefore, whereas the paratelic state of mind is powerful when it comes to being creative, it is not particularly robust when it comes to evaluating the longterm consequences or path dependencies of proposed courses of action. This is amplified by its tendency to eschew trend-based analyses. In a way, this is understandable because exploration results in the creation of a wider range of choice alternatives. This complicates their telic appraisal and limits the depth of understanding of particular choice alternatives.

\section{Rendering Daring Proposals Exploitable}

Whereas the previous pointed out how exploration plants the seeds for courses of action that at a later point in time social control agents may label as organizational wrongdoing, it does not explain how they find grounding in organizational practice. The outcomes of exploration are narratives, captured in statements and sketches from the drawing board. Yet, these deliverables cannot be implemented as such. As observed by Barry and Elmes (1997), the 
development of strategies as narrative statements is constrained by the dual requirement of being novel and credible. The grand vision needs to be rendered telic, to be objectified and captured in quantifiable constructs for them to enter the exploitative practices of the everyday life of organizations.

For example, in strategic management, the paratelic exploration of possible futures is followed, ideally, by telic analysis aimed at understanding their exploitability and assessing their propositional quality (Ramírez and Mannervik, 2016). But occasionally the outcomes of paratelic exploration become reified without being exposed to telic analysis. Likewise, in creating a new venture, the entrepreneur has -is expected to have- a business idea that sweeps the market. S/he needs to amass support and resources, for example from friends, potential business partners and venture capitalists. The proverbial elevator pitch is essentially aimed at overcoming telic skepticism and stimulating paratelic arousal and enthusiasm on the part of potential supporters. The business plan, in this respect, is a device that shrouds novelty in a telic cloak. This occurs through a process that we call telic reprocessing. Telic reprocessing has cognitive and relational aspects and acts as a substitute process for telic analysis.

Cognitive telic reprocessing. The elaboration of the outcomes of exploration makes use of “technologies of rationality” (March, 2006; cf. Cabantous and Gond, 2011). Through organizational routines such as budgeting, planning, economizing, operations analysis, strategic analysis, and business plans, daring proposals are quantified as indicators and targets, and thus made operational. When they get converted into numbers and operational processes, they assume a guise of rationality (Porter, 1995). The use of technologies of rationality is legitimized by their reliance on three components: abstractions, data, and decision rules (March, 2006, p. 203). Yet, their validity is often limited by lack of, or uncertainty about, correspondence with empirical reality. Notably, there may be uncertainty 
about the relevance of critical variables and presumed causalities in the model, reliable data may be unavailable or non-existent, and the expectation of consequences may be close to a wild guess. Therefore, instead of being elaborated through validation, the outcomes of exploration are processed to manufacture rationality (Cabantous and Gond, 2011).

Relational telic reprocessing. Cognitive telic reprocessing is reinforced by relational telic reprocessing when the outcomes of exploration are handed down within the organization for further elaboration. Their context of production, if not plain managerial instruction, gives them authority within the organization (cf. Jackall, 1988). This results in a loss of memory regarding the event and context in which they were originally developed, and all the more so if those assigned to elaborate them have a lower hierarchical status in the organization, and when their elaboration enters more advanced stages in the organization's planning routines. Thus, an important sleigh-of-hand takes place as the paratelic sources of daring courses of action get effectively hidden from sight through telic reprocessing, such that what was once imaginative, creative, and playful obtains status in the organization as something profoundly telic and rational. In this way, the ideas and visions developed in a paratelic state of mind are rationalized and made operational into the telic everyday life of the organization, to become the source of courses of action that -consistent with the consensus approach-may be labeled as instances of wrongdoing by social control agents at a later moment in time.

\section{Discussion and Conclusion}

It is all but easy to understand why occasionally some organizations end up perpetrating wrongdoing. For one, we only learn of wrongdoing after the fact, once discovered and flagged for attention. This implies that attempts at explaining the initiation of actual instances of organizational wrongdoing are necessarily post hoc, assuming, in the case of rational choice and strain theories, for example, that agents faced concrete decision options, foresaw 
material and moral consequences, and knowingly and willingly made the deliberate choice to pursue a particular course of action. But in real-life situations, the agent's experience may be different from these assumptions: decision alternatives may not be clear at all, and even if they are, their moral or material consequences may be ambiguous, equivocal, or irresolvable (Derrida, 1992). Further, the agent may experience a high level of positive arousal, stemming engagement with and immersion in her/his activity, especially when this is about exploration, which demands imagination and creativity. The outcomes of exploration may turn out to be instances or wrongdoing, but to explain them as accidents -as per one of the alternative explanations- ignores the context of their initiation.

In our argument, we therefore offer a novel proposal, based on the treatment of arousal in reversal theory, to understand the initiation of organizational wrongdoing. It takes up Warren and Smith-Crowe’s (2008) claim that the agent's experience is insufficiently acknowledged.

Our proposal builds on the argument that exploration entails a paratelic state of mind. In dealing with epistemic uncertainty, those involved in exploration act in a paratelic state of mind, in which creativity and flow prosper and a protective frame of confidence builds up and persists. Aided by the tools and techniques of exploration, and the organizational and temporal separation of exploration from exploitation, the paratelic state of mind entices its participants to be imaginative and creative in dealing with epistemic uncertainty, and thereby helps them to conceive of daring courses of action. These courses of action have an increased chance of being retained, as the paratelic state of mind leads to a selective appreciation of the material and moral risks associated with them and to a shorted temporal horizon. Subsequent telic reprocessing lends them credibility and obscures their paratelic roots, such that they may become part of the day-to-day dealings of the organization. A paratelic state of mind is required for exploration to be productive; it may result in organizational excellence but it can also be a source of future wrongdoing. 
Reversal theory has its own assumptions. Empirical evidence supports the plausibility of the basic tenets of reversal theory; we refer the interested reader to Apter (2007). We believe that the theory offers a useful vantage point to expand the body of literature that seeks to understand the initiation of organizational wrongdoing.

Accordingly, our paper makes one overarching contribution in arguing for the relevance of reversal theory for understanding the initiation of organizational wrongdoing. It elaborates the under-acknowledged experience of agents in exploration and proposes how the initiation of organizational wrongdoing may be located in the very nature of the activity and practice of exploration. This speaks to various strands of ethical decision-making theory.

\section{Implications for Theory}

First, our proposal is complementary to extant dominant and alternative explanations. It does not contradict their empirical relevance: occasionally, agents do plan to do wrong, and sometimes wrongdoing is accidental. However, it does expose and challenge some of the assumptions underlying these explanations and explores the space outside the domain covered by them (cf. Alvesson and Sandberg, 2011). Our proposal begins to explore a phenomenological understanding of the agent's experience of the situation in which s/he finds her/himself. Table 1 positions our proposal in relation to dominant and alternative explanations.

$$
===\text { Insert Table } 1 \text { about here }===
$$

As in alternative explanations, our proposal implies that organizational wrongdoing is a normal phenomenon; In contra-distinction to dominant explanations, it does not assume particular personality traits among organizational participants. However, it suggests that people, when engaged in work, alternate -reverse- between telic and paratelic states of mind. Especially those situations, tasks, or practices that call for imagination and creativity, such as when people explore new possibilities in the face of complexity, uncertainty, and 
unavailability of information, invoke the paratelic state of mind. Further, our proposal does not impose constraints on agency, as alternative explanations do, but allows for imagination, creativity and playfulness as sources for agency. This also in contrast to dominant explanations, which assume that behavior follows a positive inclination to wrongdoing that is developed after rational deliberation and calculus. Yet, the paratelic path to wrongdoing is not intentional in the sense that agents knowingly and willingly engage in illegitimate action; neither is organizational wrongdoing the consequence of mindless behavior in social situations over which agents have no control. It is unintentional in the sense that agents may become overly confident and reckless, when a protective frame of confidence and a sense of mastery prevents them from fully acknowledging the risks and dangers of their daring proposals.

Deliberate organizational wrongdoing may demand a considerable amount of creativity and ingenuity. An account thereof is missing in dominant explanations. Rational choice and strain theories do not problematize why and how people devise their wrongdoings. There is little place for creativity other than as an unproblematic step after the agent has made the conscious decision to engage in wrongdoing. Our proposal suggests that creativity stimulated in and through the paratelic state of mind- may be a first step on the route towards both wrongdoing and excellence. This step is risky, because uncertainty and ambiguity about material and moral consequences put limits to the efficacy and validity of a process of telic scrutiny, on the one hand, and because a protective frame may build up that sustains the paratelic state of mind, on the other hand.

In relation to the various alternative explanations that Palmer (2012) discusses, our proposal is related to groupthink (Janis, 1989), one of the "situational social influence” explanations. Groupthink is the phenomenon that members of a group develop a strong sense of loyalty and conformity to their group, to the consequences that they lose the ability of "independent 
critical thinking” (Janis, 1989, p. 424). Our account of reversal theory suggests that that the paratelic state of mind and the associated buildup of a protective frame can be an antecedent of groupthink. It suggests that a group's activity - exploration- and its artefacts -tools and techniques- may have affordances that stimulate groupthink. It also suggests that group homogeneity -in terms of their members' demographics and experience- and stress are moderators but not antecedents of the likelihood that groupthink establishes. Further, it addresses the problem that groupthink theory has in explaining how proposals for the adoption of "inhumane," “irrational," or "immoral” decisions or courses of action -a possible consequence of groupthink, Janis (1989) - can be brought to the table in the first place.

Second, our proposal speaks to the distinction between essentialist and consensus approaches to define organizational wrongdoing. In both approaches the account of ethics is restrictive (Kjonstad and Willmott, 1995): they put boundaries, by prior definition or by post hoc judgment, to courses of action and thereby favor the status quo rather than engaging with the possibility of novelty. These approaches to business ethics have difficulty in dealing with innovation, novelty, and creativity as they see them as inherently disruptive of the status quo (cf. Moran, 2014).

Our modification of the consensus approach, from the perspective of the social control agent to that of the agent -highlighting uncertainty and paratelic immersion in the activity- can be interpreted as leading to a plea to reinforce the conservatism of restrictive ethics. After all, if exploration can result in courses of action that are instances of organizational wrongdoing, then one could reasonably argue that exploration should be tightly controlled. However, in this interpretation, there is the risk of throwing out the baby with the bathwater, to use the colloquial expression. Exploration has brought much that is commendable and much that is regrettable. Even if there often is ground for a prudent attitude toward the novel, our modified consensus approach should not be interpreted as a plea for conservatism and a restrictive 
ethics. Precisely because of the condition of uncertainty, a Levinasian stance to ethics as leaving one's comfort zone to explore the encounter with the unknown may lead one to find not only “ethics in creativity” but also ”creativity in ethics” (Muhr, 2010; Moran, 2014).

Further, our proposal points out limitations in rational models of ethical decision-making, such as those developed by Rest (1986) and Jones (1991). Such models "have [traditionally] posited that the process of ethical decision making is cognitive, deliberate, and governed by reason” (Tenbrunsel and Smith-Crowe, 2008, p. 571). This assumption also appears regularly in the popular press and is fundamental to the presentation of evidence by prosecutors in court trials against suspects of wrongdoing. Moral deliberation in these rational models starts from choice options and dilemmas as givens, ready at hand, rather than with their production. The point of exploration is precisely to generate novel choice options. Further, and given the options at hand, there is the assumption that it is possible to make an informed choice for the morally correct option; There is little attention to how uncertainty, ambiguity, and lack of information complicate the choice. The farther away in the future and the more abstract the choice options, the less possible it becomes to develop a full understanding of their material and moral consequences.

Finally, our proposal also speaks to discussions about the role of emotions in moral judgment (Moore and Gino, 2015). Emotions are typically seen in a positive light. "Emotions provide an efficient and effective signal, without having to engage in cognitive effort, that a potential action is to be pursued or avoided” (Moore and Gino, 2015, p. 250). “The key here is that emotions point us in specific behavioral directions and amplify the strength of our moral judgments” (Moore and Gino, 2015, p. 251). Conversely, rational choice and strain explanations associate the perpetrators of wrongdoing with an absence of emotional feelings. In this light it is troublesome that "many jobs and professions are designed to intentionally mute emotional responses" (Moore and Gino, 2015, p. 251). Emotional muting is the "limited 
personal response to distress cues as well as their compromised ability to make appropriate attributions about others’ moral emotions" (Moore and Gino, 2015, p. 251).

This overview suggests that the presence of emotions acts as a positive force to enhance ethical decision making, whereas its absence or muting takes away constraints to wrongdoing. Our proposal suggests that emotions may also play another role. High positive arousal in the paratelic state of mind may prevent the sending of "an efficient and effective signal” and reduce the strength of moral judgment. Consequently, the role of emotions in understanding both organizational right-doing and wrongdoing may be more complicated than it appears in the literature.

\section{Implications for Research}

Our argument is a conceptual proposal to understand better how exploration, the activity of developing novel ideas, ultimately may result in organizational wrongdoing, as well as in organizational excellence, without recurring to an explanation that assumes culpability in terms of knowingly and willingly seeking to do wrong, nor to one that renders organizational participants mindless. Whether this plays out as we propose and what is its prevalence are questions for empirical inquiry. Depending on the specific research interest, we see at least three ways in which such research can be conducted. They build on and extend a research approach that studies business ethics as practice (Clegg et al., 2007; Painter-Morland, 2011). Firstly, ours is an argument about the possible paratelic initiation of organizational wrongdoing. What is therefore at stake is capturing the moment of its inception. This calls for fine-grained ethnographic (Rosen, 1991; Yanow, 2012; Vesa and Vaara, 2014), or even insider research (Alvesson, 2003; Brannick \& Coghlan, 2007), methods to document in great detail the early stages of exploration in activities such as strategic planning, innovation, and new venture creation. Such fieldwork needs to be unobtrusive. Obtrusive observation, such as in participation and other intervention-focused methods reduce the likelihood that those 
engaged in exploration enter or remain in a paratelic state of mind, because the very presence of the researcher-as-a-researcher can exert social control agency. Furthermore, retaining a distinct sense of distance is also important from a research ethics point of view in such research, as the ethnographer should not be held accountable for how the exploration initiative unfolds. Yet, and somewhat paradoxically, because organizational wrongdoing is flagged ex-post, there can occur circumstances in which the researcher has been accidentally present in events later flagged as wrongdoing. Such an event, though likely uncomfortable, can also be serendipitous because it allows the researcher to mobilize a potentially fascinating insider perspective on the initiation of organizational wrongdoing.

This being said, it will not be easy to conduct this kind of research as the likelihood of encountering a situation of incepting exploration initiatives that end up being labeled as misconduct cannot be determined a priori. Therefore, what might work best is simply to document the early stages of exploration processes in high detail, observing the participants’ states of mind and registering whether, how, and why any ideas put forward are rejected or retained. Doing so might reveal important insights regarding how the selective appreciation of risk and shortened temporal horizons come to be during the early stages of exploration.

Secondly, moving beyond the initial inception of paratelic daring ideas, research may focus on the processes through which such ideas are retained in subsequent organizational decisionmaking. This would call for longitudinal, potentially comparative, case study research (e.g., Pettigrew, 1990) to examine the telic reprocessing of these ideas. Questions to be studied include: How exactly are ideas transferred from idea generation to operational processes? How are daring ideas transformed to enter organizational routines such as budgeting, planning, economizing, operations analysis, strategic analysis, and business plans? How are daring ideas that typically exist as narratives (Barry and Elmes, 1997) quantified to become 
indicators and targets, and thus made operational? How is the meaning and interpretation of explorative initiatives changed when they are handed down within the organization?

Finally, abduction with the aid of historical research methods (Vaara and Lamberg, 2016) offers the possibility to re-examine interpretations of organizational wrongdoing. There is a tendency among researchers and social control agents, such as the judiciary and the mass media, to give highly telic interpretations to explain organizational wrongdoing. But, it is also possible that such interpretations overplay their hand simply because it is expedient for pursuing the case successfully in legal and administrative processes. Thus, the interpreting by researchers and social control agents may itself be a form of telic reprocessing. Careful examination of historical cases of organizational misconduct may open up possibilities for examining in detail how the establishing of wrongdoing occurred in relation to what actually took place. Whilst not seeking to sidestep questions of accountability, such studies might reveal exactly how the epistemic uncertainty can influence exploration initiatives and how organizations defend themselves against accusations of intent.

\section{Practical Implications}

If our proposal finds empirical support, then the paratelic state of mind should be frequently observed and proven relevant in situations that call for creativity and playfulness, such as exploration in strategic planning, innovation, and new venture creation. It should be clear that neither the telic nor the paratelic state of mind is good or bad in and out of itself. Yet, if exploration is done in an unmoderated paratelic state of mind, the likelihood increases that exploration produces courses of action that social control label as wrongdoing at a later stage. Likewise, as March (2006) pointed out, if exploration is done in a way that fails to initiate the paratelic state of mind, it may well result in foolishness or not produce novelty at all. The overall challenge in exploration is therefore to find a balance between (paratelic) creativity and (telic) realism. 
This challenge points to three distinct sets of practical implications that are worthy of reflection. They regard the management of exploration processes, efforts to stimulate ethical decision making more broadly, and the attitude to encountering the uncertainty and risk associated with daring ideas.

First, to the extent that exploration processes are managed, there are central roles to be played by the process owners, such as strategy managers, innovation managers, and external advisors. Process owners can stimulate the paratelic state of mind, simultaneously monitor it, and intervene in order to prevent it from persisting for undesirably prolonged periods. The point is not to prevent but to moderate paratelic behavior, as in its absence exploration will fail to generate novelty. Further, in order to prevent the paratelic state of mind from ending up dominating exploration, process owners can assume responsibility for ensuring that there is heterogeneity of views, backgrounds, competencies, and perspectives in the process, such that creative and critical thinking are in an ongoing dialogue. It is also advisable to prevent exploration from becoming the responsibility and province of a dedicated group, and to allow for plurality in participation in exploration. Diversity in participation should in particular be sought from compliance and social responsibility departments.

Second, in a broader sense, it matters what participants bring to the exploration process. Part thereof is what they have acquired in business education, such as in EMBA programs. If business education pays explicit attention to the moral responsibilities and implications of corporate behavior in business education - not as a stand-alone course but integrated in strategic management, entrepreneurship, and innovation modules, for example - they become more aware of the diverse and heterogeneous set of external expectations in light of which they need to develop exploration initiatives; It should help them to "expand their repertoire [and] improve their alertness” (Weick, 2006, p. 1724). As an initial step, these programs should move away from emphasizing a self-centered profit orientation towards adopting a 
wider stakeholder approach. Further, if companies decide to formalize their moral expectations in corporate policies (but see critical accounts of the usefulness of codes of ethics, e.g., Nyberg, 2008; Painter-Morland, 2010), then they should build on concepts such as moral integrity, phronesis, and respect and care for others. In light of the uncertainty, complexity, and lack of information in exploration to build on rule or outcome-based approaches would make the policies too restrictive (Kjonstad and Willmott, 1995).

Third, and finally, our argument points out how the many calls for radically innovative ideas and the benefits of breaking with conformity and developing novel and creative ideas, carry a risk with them of overvaluing the paratelic and suppressing the telic state of mind. At the same time, exploration will remain a significant and necessary part of corporate success. Yet, creativity cannot be managed (Styhre and Sundgren, 2005), and if it is, there is the risk of it ending up as a "technology” (Osborne, 2003). This points to an open yet prudent approach to pursuing the novel, daring ideas that result from exploration. One such approach may be found in (Deweyan) pragmatism, which emphasizes incrementalism with a permanent attentiveness to the ongoing accomplishments of the activity, reflexivity, the willingness to retrace previous steps and not to foreclose options prematurely. Another such approach may be inspired by an encounter with the novel in the form of the Other. This approach offers freedom to experiment but also demands responsiveness to Others. This may seem like a double-bind, but in effect, it is this very bind that brings about creativity in ethics and morality in creativity.

\section{Notes}

[1] We use the word 'agent' as a shorthand for one or more organizational members who act on behalf of the organization; they are employees with some level of discretion and autonomy, such as managers at various hierarchical levels in the organization or specialists. 
[2] Interpreted as strain, this demand may be a seen as a shortcut to wrongdoing, but this interpretation sidelines the agent's experience.

[3] Some of the dominant and alternative explanations that Palmer (2012) discusses deal with questions of how organizational wrongdoing perpetuates and how bystanders become implicated in wrongdoing that is already occurring.

\section{Acknowledgment}

(suppressed).

\section{Compliance with ethical standards}

None of the authors received funding for the research on which this article is based. All authors on the paper -individually and collectively- declare that they do not have any conflict of interest. 


\section{References}

Ackroyd, S. and Thompson, P. (1999). Organizational misbehaviour. Sage, Thousand Oaks, CA.

Alvesson, M. (2003). Methodology for close up studies. Struggling with closeness and closure. Higher Education 46(2), 167-193.

Alvesson, M. and Gabriel, Y. (2016). Grandiosity in contemporary management and education. Management Learning 47(4), 464-473.

Alvesson, M. and Sandberg, J. (2011). Generating research questions through problematization. Academy of Management Review 36(2), 247-271.

Apter, M. J. (1982). The experience of motivation. The theory of psychological reversals. Academic Press, London.

Apter, M. J. (1989). Reversal theory: A new approach to motivation, emotion and personality. Anuario de Psicología (42), 17-30.

Apter, M. J. (1991). A structural phenomenology of play. In J. H. Kerr and M. J. Apter (Eds.), Adult play: A reversal theory approach (pp. 13-29). Swets \& Zeitlinger, Amsterdam. Apter, M. J. (2007 [1989]). Reversal theory: The dynamics of motivation, emotion and personality, 2nd edition. Oneworld Publications, Oxford.

Apter, M. J. (2017). Ideology and societal values. Reversal theory perspective. Journal of Motivation, Emotion, and Personality: Reversal Theory Studies, 6, 1-7.

Ashforth, B. E. and Anand, V. (2003). The normalization of corruption in organizations. Research in Organizational Behavior 25, 1-52.

Barry, D. and Elmes, M. (1997). Strategy retold: Toward a narrative view of strategic discourse. Academy of Management Review 22(2), 429-452. 
Bazerman, M. H., Tenbrunsel, A. E. and Wade-Benzoni, K. (1998). Negotiating with yourself and losing: Making decisions with competing internal preferences. Academy of Management Review 23(2), 225-241.

Bazerman, M. and Tenbrunsel, A. (2011). Blind spots: Why we fail to do what's right and what to do about it. Princeton University Press, Princeton, NJ.

Brannick, T. and Coghlan, D. (2007). In defense of being "native": The case for insider academic research. Organizational Research Methods, 10(1), 59-74.

Brief, A. P. and Motowidlo, S. J. (1986). Prosocial organizational behaviors. Academy of Management Review 11(4), 710-725.

Cabantous, L. and Gond, J.-P. (2011). Rational decision making as performative praxis: Explaining rationality's éternel retour. Organization Science 22(3), 573-586.

Chugh, D., Bazerman, M. H. and Banaji, M. R. (2005). Bounded ethicality as a psychological barrier to recognizing conflicts of interest. In D. A. Moore, D. M. Cain, G. Loewenstein and M. H. Bazerman (Eds.), Conflicts of interest. Problems and solutions in business, law, medicine and public policy (pp. 74-95). Cambridge University Press, New York, NY.

Clegg, S. R., Kornberger, M. and Rhodes, C. (2007). Business ethics as practice. British Journal of Management 18(2), 107-122.

Clemente, M., Durand, R. and Porac, J. (2016). Organizational wrongdoing and media bias. In D. Palmer, K. Smith-Crowe and R. Greenwood (Eds.), Organizational wrongdoing: Key perspectives and new directions (pp. 435-473). Cambridge University Press, Cambridge.

Csikszentmihályi, M. (1990). Flow: The psychology of optimal experience. Harper Perennial, New York, NY.

Derrida, J. (1992). Force of law: The "mystical foundation of authority”. In D. Cornell, M. Rosenfeld and D. G. Carlson (Eds.), Deconstruction and the possibility of justice (pp. 3-67). Routledge, New York, NY. 
Feezell, R. (2013). A pluralist conception of play. In E. Ryall, W. Russell and M. MacLean (Eds.), The philosophy of play (pp. 11-31). Routledge, Oxford.

Fleming, P. and Zyglidopoulos, S. C. (2008). The escalation of deception in organizations. Journal of Business Ethics 81(4), 837-850.

Graffin, S. D., Bundy, J., Porac, J. F., Wade, J. B. and Quinn, D. P. (2013). Falls from grace and the hazards of high status: The 2009 British MP expense scandal and its impact on parliamentary elites. Administrative Science Quarterly 58(3), 313-345.

Greve, H. R., Palmer, D. and Pozner, J.-E. (2010). Organizations gone wild: The causes, processes, and consequences of organizational misconduct. Academy of Management Annals 4, 53-107.

Hamel, G. (1996). Strategy as revolution. Harvard Business Review 74(4), 69-82.

Huizinga, J. (1955). Homo ludens: A study of the play-element in culture. Beacon Press, Boston, MA.

Jackall, R. (1988). Moral mazes. The world of corporate managers. Oxford University Press, New York, NY.

Janis, I. L. (1989). Groupthink. In H. J. Leavitt, L. R. Pondy and D. M. Boje (Eds.), Readings in Managerial Psychology, 4th edition (pp. 439-450). University of Chicago Press, Chicago, IL.

Jarzabkowski, P. and Seidl, D. (2008). The role of meetings in the social practice of strategy. Organization Studies 29(11), 1391-1426.

Johnson, G., Prashantham, S., Floyd, S. W. and Bourque, N. (2010). The ritualization of strategy workshops. Organization Studies 31(12), 1589-1618.

Jones, T. M. (1991). Ethical decision-making by individuals in organizations. An issuecontingent model. Academy of Management Review 16(2), 366-395.

Kahneman, D. (2011). Thinking, fast and slow. Farrar, Strauss and Giroux, New York, NY. 
Kjonstad, B. and Willmott, H. (1995). Business ethics: Restrictive or empowering? Journal of Business Ethics 14(6), 445-464.

Larkin, I. and Pierce, L. (2016). Compensation and employee misconduct: The inseparability of productive and counterproductive behavior in firms. In D. Palmer, K. Smith-Crowe and R. Greenwood (Eds.), Organizational wrongdoing: Key perspectives and new directions (pp. 270-304). Cambridge University Press, Cambridge.

Lavie, D., Stettner, U. and Tushman, M. L. (2010). Exploration and exploitation within and across organizations. Academy of Management Annals 4, 109-155.

Lefkowitz, J. (2006). The constancy of ethics amidst the changing world of work. Human Resource Management Review 16(2), 245-268.

Locke, K. and Golden-Biddle, K. A. (1997). Constructing opportunities for contribution: Structuring intertextual coherence and 'problematizing' in organizational studies. Academy of Management Journal 40(5), 1023-1062.

MacLean, T. L. (2008). Framing and organizational misconduct: A symbolic interactionist study. Journal of Business Ethics 78(1), 3-16.

Mano, H. (1994). Risk-taking, framing effects, and affect. Organizational Behavior and Human Decision Processes 57(1), 38-58.

March, J. G. (1991). Exploration and exploitation in organizational learning. Organization Science 2(1), 71-87.

March, J. G. (2006). Rationality, foolishness, and adaptive intelligence. Strategic Management Journal 27(3), 201-214.

Miller, C. C. and Ireland, R. D. (2005). Intuition in strategic decision making: Friend or foe in the fast-paced 21st century? Academy of Management Executive 19(1), 19-30.

Mintzberg, H. (1994). The fall and rise of strategic planning. Harvard Business Review 72(1), 107-114. 
Moore, C. and Gino, F. (2015). Approach, ability, aftermath: A psychological process framework of unethical behavior at work. Academy of Management Annals 9(1), 235-289. Moran, S. (2014). Introduction. In S. Moran, D. Cropley and J. C. Kaufman (Eds.), The ethics of creativity (pp. 1-22). Palgrave MacMillan, Houndmills.

Moran, S., Cropley, D. and Kaufman, J. C. (Eds.) (2014). The ethics of creativity. Palgrave MacMillan, Houndmills.

Muhr, S. L. (2010). Ethical interruption and the creative process: A reflection on the new. Culture and Organization 16(1), 73-86.

Nyberg, D. (2008). The morality of everyday activities: Not the right, but the good thing to do. Journal of Business Ethics 81(3), 587-598.

Organ, D. W. (1988). Organizational citizenship behavior: The good soldier syndrome. Lexington Books. Lexington, MA.

Osborne, T. (2003). Against ‘creativity’: A philistine rant. Economy and Society 32(4), 507525.

Painter-Morland, M. (2010). Questioning corporate codes of ethics. Business Ethics: A European Review 19(3), 265-279.

Painter-Morland, M. (2011 [2008]). Business ethics as practice: Ethics as the everyday business of business. Cambridge University Press, Cambridge.

Palmer, D. (2012). Normal organizational wrongdoing: A critical analysis of theories of misconduct in and by organizations. Oxford University Press, Oxford.

Palmer, D., Smith-Crowe, K. and Greenwood, R. (2016). The imbalances and limitations of theory and research on organizational wrongdoing. In D. Palmer, K. Smith-Crowe and R. Greenwood (Eds.). Organizational wrongdoing: Key perspectives and new directions (pp. 116). Cambridge University Press, Cambridge. 
Pettigrew, A. M. (1990). Longitudinal field research on change: Theory and practice. Organization Science 1(3), 267-292.

Porter, T. M. (1995). Trust in numbers: The pursuit of objectivity in science and public life. Princeton University Press, Princeton, NJ.

Ramírez, R. and Mannervik, U. (2016). Strategy for a networked world. Imperial College Press, London.

Rest, J. R. (1986). Moral development: Advances in research and theory. Praeger, New York, NY.

Rosen, M. (1991). Coming to terms with the field: Understanding and doing organizational ethnography. Journal of Management Studies 28(1), 1-24.

Sherman, L. W. (1980). Three models of organizational corruption in agencies of social control. Social Problems 27(4), 478-491.

Sims, R. R. (1992). Linking groupthink to unethical behavior in organizations. Journal of Business Ethics 11(9), 651-662.

Smircich, L. and Stubbart, C. (1985). Strategic management in an enacted world. Academy of Management Review 10(4), 724-736.

Smith, M. (1993). Realism. In P. Singer (Ed.), A companion to ethics, 2nd edition (pp. 399410). Blackwell Publishing, Malden, MA.

Smith-Crowe, K. and Zhang, T. (2016). On taking the theoretical substance of outcomes seriously: A meta-conversation. In D. Palmer, K. Smith-Crowe and R. Greenwood (Eds.), Organizational wrongdoing: Key perspectives and new directions (p. 17-46). Cambridge University Press, Cambridge.

Styhre, A. and Sundgren, M. (2005). Managing creativity in organizations. Critique and practices. Palgrave Macmillan, New York, NY. 
Tenbrunsel, A. E. and Smith-Crowe, K. (2008). Ethical decision making: Where we've been and where we're going. Academy of Management Annals 2, 545-607.

Torsello, D. and Venard, B. (2016). The anthropology of corruption. Journal of Management Inquiry 25(1), pp. 34-54.

Tsoukas, H. and Chia, R. (2002). On organizational becoming: Rethinking organizational change. Organization Science, 13(5), 567-582.

Vaara, E. and Lamberg, J. A. (2016). Taking historical embeddedness seriously: Three historical approaches to advance strategy process and practice research. Academy of Management Review 41(4), 633-657.

Vadera, A. K. and Pratt, M. G. (2016). “Is it me? Or is it me?” The role of coactivated multiple identities and identifications in promoting or discouraging workplace crimes. In D. Palmer, K. Smith-Crowe and R. Greenwood (Eds.), Organizational wrongdoing: Key perspectives and new directions (pp. 337-369). Cambridge University Press, Cambridge. Vaughan, D. (1999). The dark side of organizations: Mistake, misconduct, and disaster. Annual Review of Sociology 25, 271-305.

Vesa, M. and Franck, H. (2013). Bringing strategy to time, studying strategy as experiential vectors. Scandinavian Journal of Management 29(1), 23-34.

Vesa, M. and Vaara, E. (2014). Strategic ethnography 2.0: Four methods for advancing strategy process and practice research. Strategic Organization 12(4), 288-298.

Warren, D. E. and Smith-Crowe, K. (2008). Deciding what's right: The role of external sanctions and embarrassment in shaping moral judgments in the workplace. Research in Organizational Behavior 28, 81-105.

Weick, K. E. (2005). Organizing and failures of imagination. International Public Management Journal 8(3), 425-438. 
Weick, K. E. (2006). Faith, evidence, and action: Better guesses in an unknowable world. Organization Studies 27(11), 1723-1736.

Werhane, P. H. (1999). Moral imagination and management decision-making. Oxford University Press, Oxford.

Winnicott, D. W. (2005 [1971]). Playing and reality, 2nd edition. Routledge, London.

Wright, J. (2016). Flow within everyday emotions and motivations: A reversal theory perspective. In L. Harmat, F. Ørsted Andersen, F. Ullén, J. Wright and G. Sadlo (Eds.), Flow experience: Empirical research and applications (pp. 197-212). Springer, New York, NY.

Yanow, D. (2012). Organizational ethnography between toolbox and world-making. Journal of Organizational Ethnography 1(1), 31-42.

Zyglidopoulos, S. C. and Fleming, P. J. (2008). Ethical distance in corrupt firms: How do innocent bystanders become guilty perpetrators? Journal of Business Ethics 78(1-2), 265274. 
Table 1: Dominant, Alternative and Reversal Theory Explanations

\begin{tabular}{|c|c|c|c|}
\hline & $\begin{array}{l}\text { Dominant } \\
\text { explanations }\end{array}$ & $\begin{array}{l}\text { Alternative } \\
\text { explanations }\end{array}$ & $\begin{array}{l}\text { Reversal theory } \\
\text { explanation }\end{array}$ \\
\hline $\begin{array}{l}\text { Organizational } \\
\text { wrongdoing as a } \\
\text { phenomenon }\end{array}$ & Abnormal & Normal & Normal \\
\hline $\begin{array}{l}\text { Explanation of the } \\
\text { initiation of } \\
\text { organizational } \\
\text { wrongdoing }\end{array}$ & $\begin{array}{l}\text { Agency, } \\
\text { premised on } \\
\text { calculative } \\
\text { rationality }\end{array}$ & $\begin{array}{l}\text { Absence of agency } \\
\text { or constrained } \\
\text { agency, } \\
\text { premised on task } \\
\text { accomplishment } \\
\text { in immediate } \\
\text { social context } \\
\end{array}$ & $\begin{array}{l}\text { Agency, } \\
\text { premised on } \\
\text { imagination, } \\
\text { playfulness, } \\
\text { creativity in } \\
\text { exploration }\end{array}$ \\
\hline $\begin{array}{l}\text { Locus of } \\
\text { explanation }\end{array}$ & Individual & Individual or group & Individual or group \\
\hline State of mind & Telic & Telic & Paratelic \\
\hline $\begin{array}{l}\text { Path to } \\
\text { wrongdoing }\end{array}$ & $\begin{array}{l}\text { Intentional } \\
\text { (mindfullness) }\end{array}$ & $\begin{array}{l}\text { Unintentional } \\
\text { (mindlessness) }\end{array}$ & $\begin{array}{l}\text { Unintentional } \\
\text { (overconfidence, } \\
\text { recklessness) }\end{array}$ \\
\hline Relevant theories & $\begin{array}{l}\text { Principal-agency } \\
\text { theory } \\
\text { (opportunism). } \\
\text { Strain theory } \\
\text { (blocked } \\
\text { aspirations) }\end{array}$ & $\begin{array}{l}\text { Pressures and } \\
\text { constraints from } \\
\text { administrative } \\
\text { systems, } \\
\text { situational social } \\
\text { influences or } \\
\text { power structures. } \\
\text { Accidents and } \\
\text { mistakes }\end{array}$ & $\begin{array}{l}\text { Reversal theory } \\
\text { Theories of play }\end{array}$ \\
\hline $\begin{array}{l}\text { Analogues from } \\
\text { classical Greek } \\
\text { mythology }\end{array}$ & Athena, Hermes * & Epimetheus ** & Dionysus $* * *$ \\
\hline
\end{tabular}

* Athena, in her capacity as goddess of reason, intelligence, warfare, and battle strategy; Hermes, in his capacity as god of trade and treachery.

** Epimetheus, Titan of afterthought and the father of excuses.

*** Dionysus, in his capacity as god of parties, festivals, madness, chaos, drunkenness, and ecstasy. 